\title{
ОСНОВНЫЕ ПРИНЦИПЫ, ПРИЕМЫ И СПОСОБЫ ВНУТРЕННЕГО ФИНАНСОВОГО КОНТРОЛЯ
}

\author{
(C) 2021 Петров А.M. \\ доктор экономических наук, профессор Департамента бизнес-аналитики \\ Финансовый университет при Правительстве Российской Федерации, Россия, Москва \\ E-mail: palmi@inbox.ru
}

Методологические аспекты оценки качества внутреннего аудита по-прежнему остаются актуальной темой. В глобальном масштабе каждое вновь сформированное правительство сталкивается с обязательством создавать, обеспечивать и поддерживать эффективный и качественный внутренний контроль с целью предотвращения мошенничества, неправильного управления и неправильного использования государственных средств, в частности на финансирование федеральных проектов. Государственные механизмы выполнения этих обязательств являются как нормативными, так и правовыми, с принятием или изменением нормативных актов, а также организационными и управленческими, такими как создание методологии проведения внутреннего аудита в государственном секторе. Реализация того или иного механизма внутреннего финансового контроля или комбинированное применение нескольких механизмов зависит от долгосрочных стратегических целей контролирующего объекта.

Ключевые слова: индикаторы, отрасль, оценка, предприниматель, риски, рынки, ситуация, стратегия, угрозы, управление, экономические субъекты.

Любого уровня контроль обеспечивается посредством соблюдения его принципов. Основные принципы внутреннего финансового контроля представлены в таблице 1 [10].

«Внутренний финансовый аудит характеризуется независимостью и объективностью результатов контрольных мероприятий. Конечная цель аудита - повышение эффективности расходования средств, а также проверка законности расходования» [6]. «Внутренний финансовый аудит представляет собой оценку надежности внутреннего финансового контроля, подготовку рекомендаций, направленных на повышение эффективности, а также разработку рекомендаций по достижению экономности и результативности расходования бюджетных средств» [11].

Изменения в части разработки плана в части организационных и управленческих структур учреждения государственного сектора иногда становится основанием окончательных резуль-

Таблица 1. Основные принципы внутреннего финансового контроля

\begin{tabular}{|l|l|}
\hline \multicolumn{1}{|c|}{ Принципы } & \multicolumn{1}{c|}{ Содержание } \\
\hline \multicolumn{1}{|c|}{1} & \multicolumn{1}{c|}{2} \\
\hline $\begin{array}{l}\text { Принцип объектив- } \\
\text { ности }\end{array}$ & $\begin{array}{l}\text { при осуществлении деятельности по планированию и проведению проверок должны } \\
\text { быть исключены предвзятость, субъективизм и предрасположенность контрольных } \\
\text { органов в отношении объекта проверки }\end{array}$ \\
\hline Принцип законности & $\begin{array}{l}\text { контрольные органы должны неукоснительно соблюдать нормы и правила, установ- } \\
\text { ленные законодательством }\end{array}$ \\
\hline Принцип гласности & $\begin{array}{l}\text { деятельность контрольных органов должна быть «открытой», а средства массовой ин- } \\
\text { формации должны обеспечивать доступ граждан к информации, содержащей резуль- } \\
\text { таты контрольно-ревизионной деятельности }\end{array}$ \\
\hline $\begin{array}{l}\text { Принцип независи- } \\
\text { мости }\end{array}$ & $\begin{array}{l}\text { контрольные органы должны иметь организационную, функциональную, материаль- } \\
\text { ную самостоятельность и независимость от государства или проверяемого субъекта } \\
\text { хозяйствования }\end{array}$ \\
\hline $\begin{array}{l}\text { Принцип ответ- } \\
\text { ственности }\end{array}$ & $\begin{array}{l}\text { контрольные органы должны надлежащим образом выполнять возложенные на них } \\
\text { контрольные функции, не превышая своих полномочий и неся полную дисципли- } \\
\text { нарную, экономическую и административную ответственность за исполнение своих } \\
\text { обязательств }\end{array}$ \\
\hline
\end{tabular}

Источник: составлено автором по материалам [10] 
татов деятельности, которые представляются и устанавливаются внутренними контролерами (аудиторами). Следовательно, правильное применение методов, подходов и критериев оценки качества внутреннего контроля не является самоцелью - это необходимость и важное условие устойчивого развития субъекта хозяйствования.

В системе управления организациями и учреждениями внутренний финансовый контроль (далее - ВФК) считается центральным элементом в устойчивом развитии. Охватывая весь управленческий цикл, внутренний финансовый контроль должен способствовать подтверждению эффективного использования средств, выявлению рисковых «полей» деятельности, сохранению финансовой устойчивости субъекта хозяйствования в быстро меняющихся условиях.

В процессе функционирования ВФК выработал свои методы в системе экономических наук. Модель методического обеспечения внутреннего финансового контроля представлена на рисунке 1.

Рассмотрим подробнее действующие методики организации ВФК на государственном уровне. Федеральный закон № 83-Ф3 «О внесении изменений в отдельные законодательные акты Российской Федерации в связи с совершенствованием правового положения государственных (муниципальных) учреждений» [3] обеспечил правовые условия для сокращения внутренних издержек организаций государственного сек- тора и привлечения внебюджетных источников обеспечения, согласно которому бюджетные, автономные учреждения (далее - БУ, АУ соответственно) стали функционировать по средствам финансирования через субсидирование выполнения государственных заданий, доведенных до учредителей (далее - Учредитель).

Бюджетные и автономные учреждения получили больше независимости при расходовании указанных субсидий, но, на практике существует сложившаяся тесная взаимосвязь между Учредителем и его подведомственными учреждениями. Учредитель продолжает осуществлять сплошной контроль в отношении «подведомственных учреждений».

Основные положения внедренного на федеральном уровне ВФК установлены ст. 160.2.1 БК [1] и принятым в развитие правовых норм постановлением Правительства РФ от 17 марта 2014 года № 193 (далее - Правила осуществления ВФК и ВФА). ВФК уже представляется как непрерывный процесс, реализуемый должностными лицами субъектов ВФК, соответствующий принятой международной практике. Однако ВФК идет в разрез с установившимся представлением о деятельности «контрольных» подразделений (должностных лиц), принятым ранее в отечественной практике. Это несоответствие требует устранения.

Поскольку ВФК и внутренний финансовый аудит (ВФА), осуществляемые главными адми-

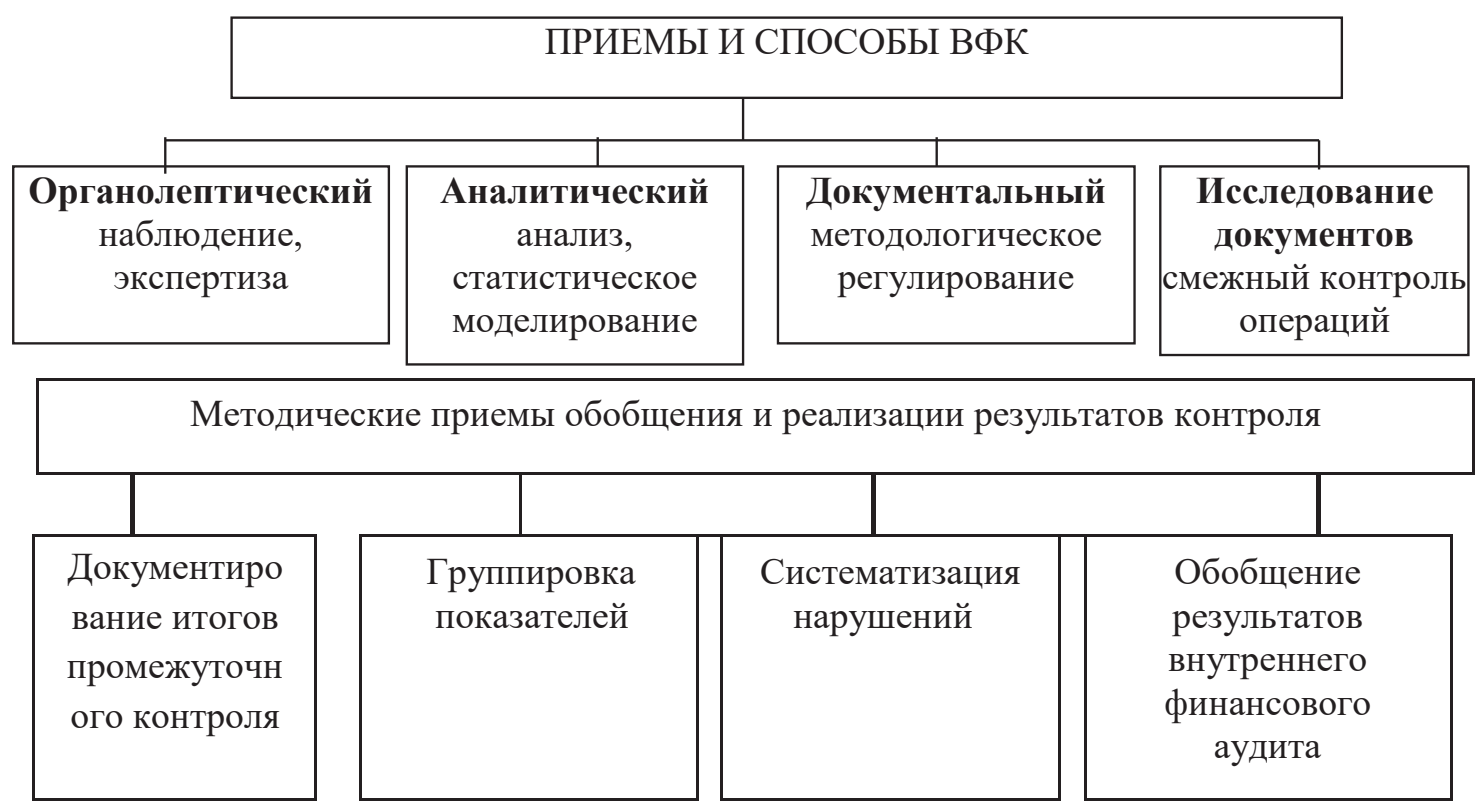

Рисунок 1. Модель методического обеспечения внутреннего финансового контроля Источник: составлено автором 
нистраторами бюджетных средств (ГАБС), администраторами бюджетных средств (АБС) являются предметом аналитической деятельности учреждений государственного финансового контроля (ГФК), Федеральное казначейство, органы ГФК субъектов, проводят анализ осуществления главными администраторами бюджетных средств ВФК и ВФА [2].

Целями осуществления ВФК в бюджетном секторе являются: проверка соблюдения бюджетного законодательства и внутренних локальных актов; проверка целевого использования бюджетных средств; осуществление внутренних мероприятий учреждения, направленных на повышение результативности и рациональности использования бюджетных средств.

Действенность внутреннего финансового контроля для всех субъектов хозяйствования обеспечивается посредством стандартизации. Стандартизация выступает важным исходным условием при настройке системы ВФА в организации государственного сектора. Соответствие стандартам обеспечивает объективную интерпретацию и оценку информации о работе государственного сектора экономики. Стандартизация способствует адекватной и последовательной оценке работы уполномоченных подразделений, а также стандартизация является одним из обязательных условий нормального функционирования указанных систем.

Система стандартов ВФА будет определять ключевые принципы, положения и процедуры для организации внутреннего государственного финансового контроля (ВГФК). Заметим, что при отсутствии единых методологических подходов снижается эффективность ВФА в целом.

Международный опыт стандартизации деятельности подразделений ВФА подтверждает необходимость в единой методологии и методике для всех уровней бюджетной системы. При внесении соответствующих изменений правовой базы, необходимо учитывать международную концепцию внутреннего контроля COSO (Комитет спонсорских организаций Комиссии Тредуэя) [5]. Пять компонентов COSO - контрольная среда, оценка риска, информация и коммуникация, мониторинг и существующие контрольные действия обуславливают сущность и значение концепции.

Изменения в БК РФ, внесенные ФЗ от 26 июля 2019 г. № 199-ФЗ, с 01 января 2020 г. определили осуществление внутреннего аудита в со- ответствии с федеральными стандартами, установленными Минфином России (пункт 5 статьи 160.2-1 Бюджетного Кодекса в редакции Федерального закона № 199-ФЗ).

ВФК - это процесс, приносящий пользу субъектам хозяйствования посредством предоставления разумных ожиданий в части: эффективности (результативности) операций; достоверности финансовой отчетности; соответствия действующим законам и правилам; защите активов.

О.Ю.Амбарнова и Т.В.Варкулевич отдают предпочтение математически рассчитанному материальному эффекту при оценке эффективности внутреннего контроля [4]. А.Тихомиров считает, что эффективность внутреннего контроля определяется на основе отношения корпоративной прибыли, полученной в результате мер, предусмотренных внутренним контролем, к расходам, связанным с деятельностью.

И.В.Хорло отмечает, что эффективность системы внутреннего контроля определяется с помощью показателей сокращения затрат в результате работы системы управления, и предлагает применять математические модели для оценки эффективности внутреннего контроля [12].

Эффективная финансово-хозяйственная деятельность экономических субъектов обеспечивается посредствам внутреннего контроля, мониторинга и оценки рисков, сопровождающих бизнес-процессы. Под риском понимают вероятность наступления требований событий, влекущих негативные последствия разной степени ущерба.

Управление рисками определяется как комплекс методических, организационных и информационно-аналитических мероприятий по выявлению и предотвращению рисков, оценке эффективности мероприятий, а также по организации работы в части совершенствования управления рисками.

В теории государственного управления понятие бюджетного риска стали исследовать более подробно лишь последние десятилетия. Риск всегда связан с неопределенностью, при этом бюджетная деятельность достаточно предсказуема. Однако, вопрос управления рисками является ключевым в системе реформирования финансового менеджмента бюджетной сферы. И весьма важным в управлении рисками является использование адекватной системы ВФК. 
Внутренний контроль в государственном секторе, помимо применения систематического подхода, основывается на применении процесса оценки и повышении эффективности управления рисками. Такой подход охватывает последовательность действий, которые преобразуют ресурсы внутреннего финансового контроля (аудита) и показывают конечные результаты. Связь и зависимость между качеством, описывающим характеристики внутреннего финансового контроля и отражающим его существенные свойства, а также относительные показатели эффективности всегда были и будут предметом различных исследований. Проблема практики определяется степенью влияния эффективности и результативности на качество внутреннего финансового контроля в государственном секторе.

Основная проблема внутреннего финансового контроля заключается в определении эффективности и результативности деятельности субъекта хозяйствования, эффективности потребления финансовых ресурсов и минимизации влияния всевозможных рисков. В целом можно предположить, что эффективность внутреннего финансового контроля заключается в достижении поставленных целей и выполнении поставленных задач, а результативность - в проведении внутреннего финансового контроля с наименьшим количеством ресурсов, способствуя формированию добавленной стоимости для организаций государственного сектора.

Методика внутреннего финансового контроля выражается в комплексном подходе реализации пяти взаимосвязанных ключевых этапов, которые в совокупности позволяют определить уровень эффективности функционирования системы внутреннего контроля, ориентированной на риск:

1. Определение содержания ВФК.

2. Отбор показателей для ВФК.

3. Обоснование системы показателей эффективности функционирования ВФК.

4. Выбор ключевых показателей эффективности функционирования ВФК, разработка методики их оценки.

5. Формирование матрицы ключевых показателей, определение обобщающего показателя эффективности функционирования ВФК и его оценка.

Основной задачей при разработке комплексного метода является создание научнообоснованного методологического аппарата, который в совокупности позволит определить уровень эффективности функционирования ВФК путем выявления и обоснования определенного обобщенного числового показателя, характеризующего уровень функционирования ВФК, путем осуществления органолептического метода ВФК.

Применение комплексного подхода ВФК в определенной последовательности (этапности) может изменить содержание контрольных процедур во время контроля с учетом изменений в организации ВФК.

Важность первого этапа определена содержанием ВФК, четким понятийным аппаратом.

Второй этап комплексного подхода проводится с целью выявления и подбора доступных возможных показателей, характеризующих эффективность функционирования ВФК.

Реализация третьего этапа предполагает отбор системы показателей эффективности работы ВФК и их научное обоснование.

Для определения перечня показателей эффективности работы ВФК необходимо: выявить факторы, влияющие на функционирование ВФК; изучить подходы к оценке эффективности ВФК по показателям; проанализировать информацию, полученную в ходе проведенных мероприятий; сформулировать соответствующие показатели функционирования указанной системы исходя из влияния факторов.

Четвертый этап нацелен на выбор ключевых показателей эффективности ВФК и разработку методики их оценки.

Заключительный этап нацелен на формирование матрицы ключевых показателей, определение обобщающего показателя эффективности ВФК и его оценки.

\section{Библиографический список}

1. «Бюджетный кодекс Российской Федерации» от 31.07.1998 № 145-Ф3 (ред. от 01.10.2020)// СПС КонсультантПлюс.

2. Федеральный закон от 26.07.2006 N 135-Ф3 (ред. от 24.04.2020) «О защите конкуренции» // СПС КонсультантПлюс. 
3. Федеральный закон от 08.05.2010 N 83-ФЗ (ред. от 26.07.2019) «О внесении изменений в отдельные законодательные акты Российской Федерации в связи с совершенствованием правового положения государственных (муниципальных) учреждений» // СПС КонсультантПлюс.

4. Амбарнова, О. Ю., Варкулевич, Т.В. Система внутреннего контроля и ее интегральная оценка - как инструмент улучшения показателей страховых компаний // АНИ: Экономика и управление.-2017.- 2 (19).- С. 15-19.

5. Мельник, М.В. Международные стандарты ISSAI и INTOSAI GOV, структура, содержание и практика применения высшими органами финансового контроля // Бухгалтерский учет, аудит и статистика. - 2012.№ 6.- С. 135-144.

6. Петров А. М., Бурцева К. Ю. К вопросу организации внутреннего финансового контроля в рамках расходования средств на федеральные проекты // Экономические науки. - 2020. - № 188. - С. 113-119.

7. Петров, А. М. Оперативный и превентивный инструментарий реализации внутреннего финансового контроля в рамках расходования средств на федеральные проекты // Экономические науки. - 2020. - № 185.С. 169-178.

8. Саввина, О.В. О современной модели финансового надзора // Финансы и кредит. - 2015.- № 34 (658).- С. 47-57.

9. Кучеров, А.В. Внутренний аудит в России / А.В.Кучеров, Е.В.Леушина.- Текст: непосредственный, электронный // Молодой ученый._ 2013. - № 6 (53). - C. 359-362._ URL: https://moluch.ru/archive/53/7029/.

10. Кришталева, Т.И. Теория и методология взаимодействия контроля и налогообложения: монография / Т.И. Кришталева; Изд.-торговая корпорация «Дашков и К».- Москва: Дашков и Кㅇ, 2008. - 309 с.

11. На 13,5\% снизилась смертность в результате ДТП на подведомственных Росавтодору трассах // Федеральное дорожное агентство Росавтодор: [сайт].- 2019.- 17 октября.- Текст: электронный.- URL: https:// rosavtodor.ru/press-center/news/293571.

12. Horlo I.V. (2007). Application of mathematical models for assessment of effectiveness of the system of internal control. Economic and mathematical simulation, 4 (85), 57-61.

13. Chernysheva N.A., Perskaya V.V., Petrov A. M., Bakulina A.A. GREEN ENERGY FOR BELT AND ROAD INITIATIVE: ECONOMIC ASPECTS TODAY AND IN THE FUTURE / International Journal of Energy Economics and Policy. 2019. T. 9. № 5. C. $178-185$.

14. Kevorkova Z.A., Petrov A. M., Savina N. V. TOWARDS LIABILITIES OF CORPORATE SYSTEMS / International Journal of Civil Engineering and Technology. 2019. T. 10. № 2. C. 1582-1593.

15. Petrov A.M., Nikiforova E. V., Kiseleva N.P., GrishkinaS.N., Lihtarova O. V. CREATION OF THE REPORTING ON SUSTAINABLE DEVELOPMENT OF COMPANIES BASED ON SOCIOECONOMIC MEASUREMENT STATISTICS / International Journal of Recent Technology and Engineering. 2019. T. 8. № 2. C. 4005-4012.

16. SotnikovaL.V., PolenovaS.N., MislavskayaN.A., PetrovA.M., BasovaM.M. SUSTAINABLE DEVELOPMENT, MACRO AND MICRO LEVEL: RUSSIAN AND FOREIGN MODEL / International Journal of Recent Technology and Engineering. 2019. T. 8. № 2. C. 4524-4532.

17. Kosolapova M.V., Muravitskaya N.K., TolmachevM.N., MelnikovaL.A., PetrovA.M. TECHNOLOGY FOR SOLVING THE PROBLEMS RELATED TO THE IMPLEMENTATION OF THE CONCEPT OF PRESERVING CAPITAL IN ACCOUNTING AND STATISTICS / International Journal of Recent Technology and Engineering. 2019. T. 8. № 3. C. 789-792.

18. Kosolapova M.V., PetrovA.M., YshanovI.G., Muravitskaya N.K., NurmuhamedovaH.S. THE ECONOMIC SIGNIFICANCE OF STATISTICAL RESEARCH ACTIVITIES OF REPRESENTATIVE OFFICES OF COMPANIES ABROAD / International Journal of Innovative Technology and Exploring Engineering. 2019. T. 8. № 10. C. 27132722.

19. Petrov A.M., Yurasova I. O., Putihin Y.E., Poluleh M. V., Erohina V.N. ACCOUNTANT MODELING TECHNOLOGY AND STATISTICS IN THE CONTEXT OF THE NEW EDUCATIONAL CONCEPT / International Journal of Innovative Technology and Exploring Engineering. 2019. T. 8. № 12. C. 3214-3217.

20. Petrov A.M., Kiseleva N.P., KevorkovaZ.A., Melnikova L.A., YshanovI.G. PRESENT DEVELOPMENT PRACTICES FOR TAX, FINANCIAL AND STATISTICAL REPORTING IN THE RUSSIAN FEDERATION / International Journal of Innovative Technology and Exploring Engineering. 2019. T. 8. № 12. C. 3538-3542.

21. Karpova T.P., PetrovA.M., Antonova O. V. DIRECTIONS OF ACCOUNTING DEVELOPMENT IN THE CONDITIONS OF DIGITALIZATION / Journal of Advanced Research in Dynamical and Control Systems. 2018. T. 10. № 7 Special Issue. C. 117-125.

22. Lymar M.P., Kevorkova Z. A., Petrov A. M. THE CONVERGENCE OF NATIONAL AND INTERNATIONAL ACCOUNTING STANDARDS: CHINESE EXPERIENCE / International Journal of Civil Engineering and Technology. 2018. T. 9. № 13 . C. $82-94$. 